\title{
Online Learning Evaluation during Covid-19 using CSE-UCLA Evaluation Model at English Education Department Universitas Kristen Indonesia
}

\author{
Lamhot Naibaho \\ Universitas Kristen Indonesia \\ lamhot.naibaho@uki.ac.id
}

\begin{abstract}
This research is about the online learning evaluation during covid19 using the CSE-UCLA evaluation model. It is was aimed to evaluate the implementation of online learning during COVID-19. This research was done at Universitas Kristen Indonesia (UKI) using a qualitative approach with an evaluative study design is the CSE-UCLA evaluation model design. The subjects of this study were lecturers and students and were taken through purposive sampling. The instruments used in this research were questionnaires and interviews, observations, and documentation. The data analysis technique used in evaluating online learning use at the UKI is based on the assessment system components, program planning, program implementation, program improvement, and including good criteria, in terms of quality level improvement programs including good program certification. The study's result was that, in general, the quality level of the online learning used at the UKI is already in good criteria. When viewed from the component system assessment level of quality including good criteria, in terms of quality level planning program including good criteria, in terms of quality level implementation of the program criteria, and when viewed from quality level certification programs also include good criteria.
\end{abstract}

Keywords

online learning, evaluation; Covid-19; CSE-UAAmodel

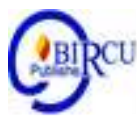

\section{Introduction}

The spread of the coronavirus pandemic or COVID-19 in Indonesia caused many universities and schools to "stop the process of face-to-face learning instead of online learning" [1]. Minister of Education and Culture also "seeks to build cooperation with various parties that focus on developing online education systems. The application of online learning requires both parties' readiness, both from the education service provider or the students themselves" [2]. However, online and distance learning requires the help of qualified and easily accessible technology. Besides, students must also be prepared to adapt to changes in learning that schools and universities govern. Online learning can be seen more freely and flexibly accessed from home.

As the development of the digital world is very significant, the behavior of journalistic production has shifted the medium used. This shift can be seen through the report data "Perspective from the Global Entertainment and Media Outlook 2017" states that the global pace of newspaper growth in the next five years is minus 8.3 percent. Whereas for other conventional mass media (magazines, radio, television, and books) also experienced minus growth at only 3.4-6 percent. On the other hand, PwC predicts internetbased media to grow 0.5 to 6 percent (Pujilestari in Wahid et al, 2020) 
The learning process that "occurred in tertiary institutions in the era of advancement in information technology today has experienced a shift in approach that initially used a face-to-face approach between lecturers and students, which occurred directly in the classroom into an online approach through the use of online learning" [3]. The need for online learning facilities at tertiary institutions becomes very important due to several considerations, among others: "online learning is easy and fast to be used to help the learning process both in class and outside the classroom, through online learning, students will have the strength or ability to can explore or search for, deepen, and expand the course material they learn through various online learning resources, with online learning culture of learning will be formed, and through online learning also encourages expression in students to want to learn to explore knowledge and information actively" [4].

The development of technology, communication and information, especially the internet has become a demand for teachers in Indonesia to be able to use it as a source of positive learning media in supporting teaching and learning processes. The use of technology media provides benefits for teachers and students to access learning materials and interact directly in learning in the classroom, and also outside the classroom through online media. (Prasasti, et al. 2019)

The basic assumptions of online learning are: a) easy and fast to use; b) the interconnection power of exploration, deepening, and expansion of material from various sources; c) encourage the expression of learner autonomy; and d) encourage the creation of a learning culture. "Online learning is a form of educational service that can help students carry out the learning process both in the classroom and outside the classroom without the separation between space and time" $[5 ; 6]$. Online learning, which is generally used in a tertiary environment, is to utilize web-based technology.

In general, online learning in the learning process has been very much needed in almost all universities in Indonesia and is no exception to Universitas Kristen Indonesia (UKI). UKI, as one of the tertiary institutions in the process of developing towards "Digital University", utilizes online learning as a facility to help expedite the learning process that occurs between students and lecturers both in the classroom and outside the classroom, so that if the lecturer is unable to attend during teaching hours, the learning process can still be implemented.

In order to reduce the rate of spread of COVID-19, the Rector of UKI adopted several policies. They are: a) stop the face-to-face learning that is usually carried out on campus, b) learning continues to run using the online learning system through the means of Google hang out, zoom, and also teams; lecturers and education personnel do "work from home" but are still allowed to come to campus for things that are very important and must be done on campus. To optimize online learning, some things that are done at UKI are as follows: managing the time - lecturers manage the study time regularly, and students must do the assignments that are charged by lecturers properly; Preparing the technology needed - Students must know what equipment is needed to do online learning. Not all campuses already provide adequate online learning services. Therefore several online learning platforms can be an alternative. Likewise, technological tools such as computers, smart devices or tablets are essential and especially internet-worthy networks; Learning seriously - the temptation to watch videos, access social media, to read news content impulsively is often done without prior plans. Therefore, students need to try to focus and be consistent during the specified study time. Avoid all kinds of distractions that can interfere with the learning process and speaking politeness - "for those who are not accustomed to online learning must adjust to be constantly visible and communicate responsively with teachers or other classmates. If needed, a particular group should also be held to discuss the tasks 
assigned by the instructor. Although it does not have to be done face-to-face, communication must be well established to avoid misunderstanding" [7]. If they are not sure of the work's results, students are expected to contact the lecturer immediately. In the "spread of the COVID-19 coronavirus, online learning like this can actually be an effective alternative to direct face-to-face class meetings" [8].

Although online learning has been implemented at UKI before and during the COVID-19, its implementation has never been evaluated yet. This condition encourages the researcher to evaluate the implementation of online learning at UKI using CSE-UCLA as the evaluation model of online learning. It is done in order to evaluate the implementation of online learning during COVID-19 at UKI.

\section{Review of Literature}

The term program means a plan. Suppose this program is directly linked to program evaluation. In that case, the program is defined as a unit or activity unit that realizes or implements a policy, takes place in a continuous process, and occurs in an organization that involves a group of people. What are the reasons for conducting program evaluations? Furthermore, when did program evaluation become popular? Serious thinking about program evaluation began around the eighties. Since the 1979's, there have been developments concerning concepts related to program evaluation. A program is not just a single activity that can be completed quickly but is continuous because it implements a policy. Therefore, a program can last a relatively long period

In a broad sense, evaluation is a process of planning, obtaining, and providing necessary information for making alternative decisions. Following this definition, each evaluation or assessment is a deliberately planned process to obtain information or data; based on these data, decide. After a research object has been collected, the data must be appropriate and support the planned evaluation's objectives.

Evaluation is "an activity to collect, analyzes, and presents information about a particular object under study, and the results can be used for consideration in making a decision. The definition is also strengthened by the opinion states that evaluation is an activity to collect data, data analysis and presentation data to be information about a particular object under study so that the results can be used to make decisions" [9; 10]. "Evaluation is an activity that consists of the process of gathering, describing and presenting various information about the course of things that can later be used as a basis for drawing conclusions and recommendations" [11]. Evaluation is "an activity to collect, understands, and reports the results of an analysis of a particular program/object so that the results can be used for consideration in making a decision whether the program is continued or stopped" $[12 ; 13]$.

Based on some of these opinions, evaluation is "an activity carried out by evaluators to collect, analyze, and present the analyzed data into useful information as a basis for deciding to continue or stop a program/object" [14]. An evaluation activity "is implemented not to look for errors or weaknesses based on evaluating an object or program being evaluated" [15]. However, the most important thing is to know the level of effectiveness of an object that can run well and know the weaknesses that cause an object or program cannot run properly, so it needs to be recommended to improve or improve the weaknesses found.

Therefore, from some weaknesses in utilizing online learning at UKI, it is necessary to evaluate. To be able to evaluate correctly, an evaluation model is needed. The selection of an evaluation model that is appropriate and matches the object being evaluated will 
impact and be helpful in decision-making. It is following the opinion of "The evaluation model is instrumental in helping data retrieval as material for decision making, evaluation can also be used for decision making whether continued, stopped, or made modifications" [16].

The research results that form the basis so that this research needs to be carried out is a research which is about evaluating online learning management programs with the following results: (1) the readiness of lecturers in implementing online learning based learning programs from the context aspect is low. From the input aspect, it is low. From the process aspect, it is in the high category, and from the product aspect, it is in a low category (2) the online learning development team's readiness in preparing and implementing an online learning-based learning program from the context aspect is very high. From the input aspect, it is very high, from the process aspect, it is high, and from the product aspect, it is very high (3) students' readiness in participating in online learning based learning from the context

Aspect is very high. From the input aspect, it is high that it is low from the process aspect, and from the product aspect, it is in a low category (4) the availability of facilities and infrastructure to support online learning-based learning is complete and adequate to support learning activities [17].

The obstacle found in the research conducted was that the university was not able to optimally show evidence of efforts to socialize the use and benefits of online learning to the entire academic community in supporting the learning process [18]. To improve the results of this study, the CSE-UCLA model in evaluating the use of online learning. This model is very appropriate for evaluating online learning because it is equipped with a program implementation component that can provide an overview of the socialization efforts that have been carried out. The CSE-UCLA model is suitable for evaluating service programs, one example of which is online learning [19].

The "CSE-UCLA model is an evaluation model that has five evaluation dimensions (system assessment, program planning, program implementation, program improvement, and program certification) and is suitable for evaluating service programs that help human life, such as library programs, banks, cooperatives, e-government, online learning and others" [20]. The "CSE-UCLA model is an evaluation model that has five evaluation dimensions, including system assessment which provides information about the state of the system, program planning that helps select specific programs to meet program needs, program implementation which prepares information to introduce programs, improvement programs that provide information about program function/performance, program certification that provides information about the benefits or uses of the program" [21].

The purpose of this research is to find out information about the level of quality of online learning utilization at the Indonesian University of Technology, seen from the perspective of the "components of the CSE-UCLA evaluation model, which consists of system assessment, program planning, program implementation, program improvement and program certification" [23]. After knowing the research objectives, it is also necessary to know the benefits of this research, namely, to make it easier for evaluators to obtain information related to the quality level of online learning utilization at the UKI from the components' point of view of the CSE-UCLA evaluation model. 


\section{Research Methods}

The approach used is a qualitative approach with an evaluative study design using is the CSE-UCLA evaluation model design. The object under study is online learning which is utilized in the learning process, it was done at UKI during the COVID-19, and the subjects of this study were lecturers and students. Determination of the subject uses a purposive sampling technique to dig up information as deep as possible to the parties that are related and have a direct interest in online learning. The method used in data collection is through questionnaires and interviews, observations, and documentation. The data analysis technique used in evaluating the use of online learning at the UKI is based on the assessment system components, program planning, and program implementation, and program improvement, namely quantitative descriptive analysis techniques. Data analysis of the weaknesses found in online learning at UKI uses descriptive qualitative analysis techniques.

\section{Results And Discussion}

Several "aspects have been measured in evaluating the use of online learning based on the components of the CSE-UCLA model using the main instruments in the form of questionnaires and auxiliary instruments in the form of interview guidelines, observations, and documentation" [24;25]. Aspects that have been measured in the system assessment component include a) the legal basis for implementing online learning; b) planning of learning models based on online learning; $c$ ) mechanism for determining human resources [26]. Aspects that have been measured in the planning program component include: a) the readiness of lecturers' knowledge, b) the readiness of students' knowledge, c) the readiness of managers' knowledge, d) the readiness of facilities and infrastructure, e) the organizational structure of the online learning board, and f) budget readiness.

The aspects that have been measured in the program implementation component are a) socialization of the introduction of online learning to the academic community, b) socialization of the operation of online learning for lecturers and students, and c) socialization of the use of crucial devices and support learning to managers. Aspects that have been measured in the improvement program components include a) budget management, b) hardware installation, c) software installation, and d) online learning operation. Aspects that have been measured in the certification program component area) user satisfaction, b) system reliability, and c) the quality of the learning process.

To determine the level of quality of online learning utilization is done by comparing the percentage of standard determinants of evaluation quality with the percentage of evaluation results of online learning utilization. The standards for determining the quality of evaluation have been set to evaluate the use of online learning. Criteria or categorizing standards determining the quality of online learning utilization can be described as follows: a) very good, with a range of 90-100 percentages, b) good, with a range of percentages 8089, c) enough, with a range of percentages $70-79$, d) less, with a range of percentages $60-$ 69 , and e) significantly less, with a range of percentages $<59$.

The description of the evaluation quality determination standards that have been defined to evaluate the utilization of online learning at UKI based on each component and evaluated aspects. The evaluation research results using the CSE-UCLA model in terms of system assessment components, program planning, program implementation, and program improvement. 
Suppose you look back at the quality determinant standards and evaluation results of online learning utilization. In that case, there is a percentage increase in the quality of online learning utilization in terms of the system assessment component, amounting to $0.66 \%$, the percentage increase in the quality of online learning utilization in terms of program planning components, namely $0.15 \%$. The percentage increase in the quality of online learning utilization in terms of the program implementation component is $0.14 \%$, the percentage increase in the quality of online learning utilization in terms of the improvement program component is $0.89 \%$. The percentage increase in the quality of online learning in terms of the program certification component is $0.90 \%$.

\section{Quality Determinant Standard}
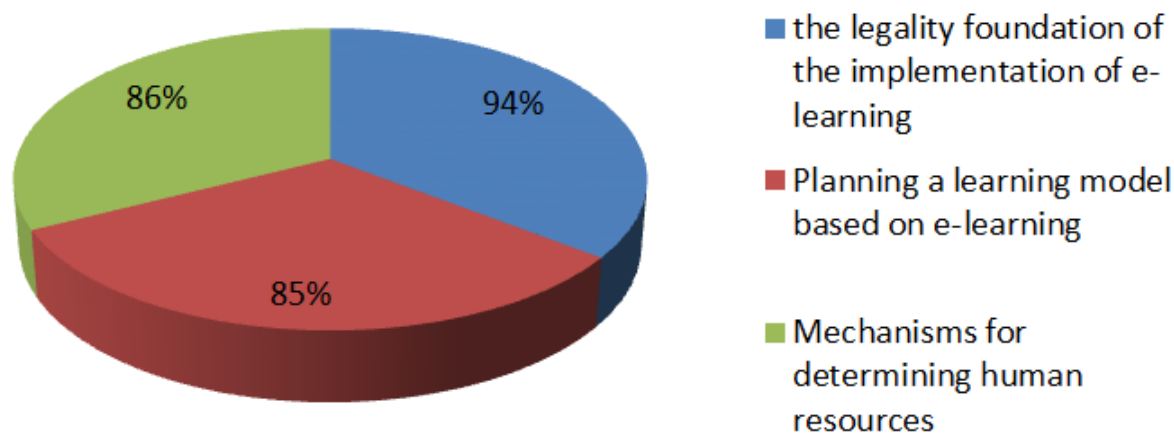

Figure 1. Quality Determining Standard of Assessment System

In general, the quality level of online learning utilization in terms of the assessment system component obtained $88.33 \%$, so the quality of online learning utilization, when viewed from this component, is included in good criteria and meets the evaluation quality standards set. It follows the evaluation results compared to the standard quality determinants of evaluation on the components of the assessment system that have been previously set at $88.00 \%$. 


\title{
Quality Determinant Standard
}
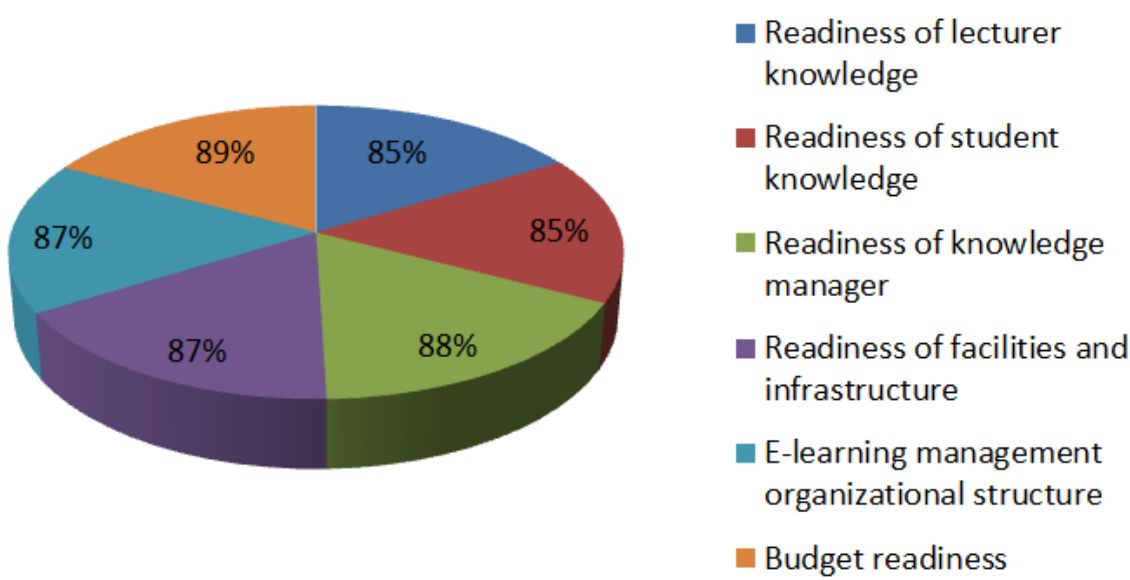

Figure 2. Quality Determining Program Planning

The quality of online learning utilization in terms of program planning components obtained a percentage of $87.47 \%$, so the quality of online learning utilization, when viewed from this component, is included in good criteria and meets the evaluation quality standards set. It follows the evaluation results compared to the standard quality determinants of evaluation on the components of the planning program that have been previously set at $87.33 \%$.

\section{Quality Determinant Standard}

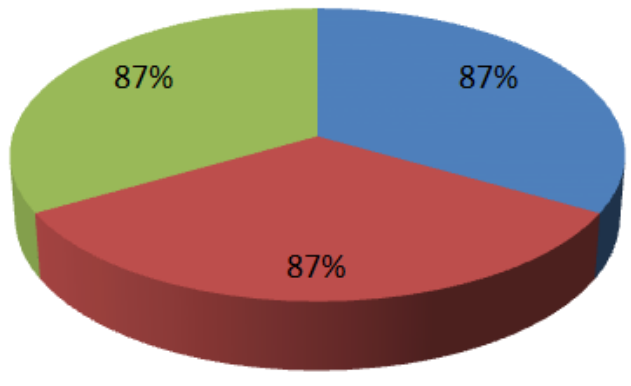

\author{
- Socialization of \\ introduction to e-learning \\ for academicians \\ - Socialization of e-learning \\ operations for lecturers \\ and students \\ socialization of the use of \\ the main tools and \\ supporting e-learning to \\ managers
}

Figure 3. Quality Determining Standard of Program Implementation

The quality of online learning utilization in terms of the program implementation component obtained a percentage of $88.13 \%$, so the quality of online learning utilization, when viewed from this component, is included in good criteria and meets the quality evaluation standards set. It follows the evaluation results compared to the evaluation quality determinant standards in the implementation program components that have been previously set at $88.00 \%$. 


\title{
Quality Determinant Standard
}

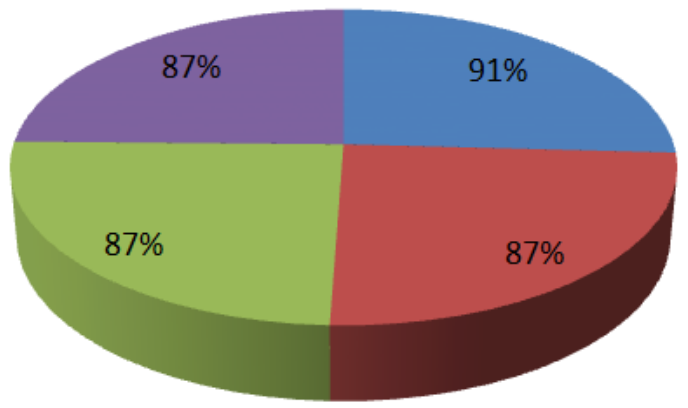

Budget management

- Hardware installation

- Software installation

E-learning operations

Figure 4. Quality Determining Standard of Program Improvement

The quality of online learning utilization in terms of improvement program components obtained a percentage of $88.00 \%$, so the quality of online learning utilization, when viewed from this component, is included in good criteria and meets the evaluation quality standards set. It follows the evaluation results compared with the standard quality determinants of evaluation on the improvement program components that have been previously set at $88.00 \%$.

\section{Quality Determining Standard}

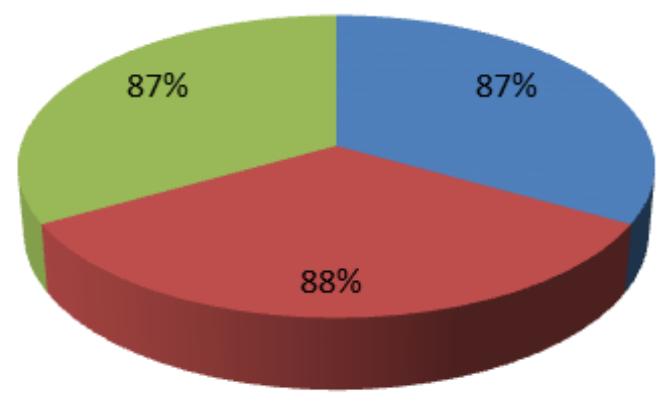

\author{
- User satisfaction \\ - System reliability \\ Quality of the learning \\ process
}

Figure 5. Quality Determining Standard of Program Certification

The quality of online learning utilization in terms of the certification program component obtained a percentage of $89.13 \%$, so the quality of online learning utilization, when viewed from this component, is included in good criteria and meets the quality evaluation standards set. According to the evaluation results, it is compared to the evaluation quality determinant standards in the certification program component that has been previously set at $88.33 \%$. 
There are several obstacles in conducting evaluation research using this CSE-UCLA model on the use of online learning at the University of Technology in Indonesia, among others as follows: (1) in the system assessment component, especially aspects of the 'mechanism of determining human resources, it is found to be difficult in determining the mechanism of screening human resources according to their fields and able to manage online learning well (2) the program planning component, which is the aspect of the readiness of lecturers' knowledge, found obstacles in the case that there are still lecturers who are not ready to get to know and are also not ready to use online learning for their teaching needs. In the 'student knowledge readiness' aspect, there were also obstacles if there were still students who did not know about online learning facilities at UKI. The aspect of 'the readiness of facilities and infrastructure' also found obstacles that are not yet complete facilities and infrastructure needed to run online learning optimally. Likewise, on the 'budget readiness' aspect, which is a constraint in preparing a budget to realize online learning at UKI? (3) the program implementation component, which is 'the socialization aspect of the operation of online learning for lecturers and students, also found obstacles that are rarely any socialization activities of online learning as a whole for the academic community at the UKI (4) in the improvement program component, 'namely, the introduction aspect of the online learning system for lecturers and students, also found obstacles that are there are lecturers and students who cannot operate online learning well $[27 ; 28 ; 29]$. It is necessary to give recommendations for the right solution to the problems found to overcome these obstacles

\section{Conclusion}

Based on the evaluation results and several discussions previously explained, it is concluded that, in general, the quality level of the online learning used at the UKI is already in good criteria. When viewed from the component system assessment level of quality including good criteria, in terms of quality level planning program including good criteria, in terms of quality level implementation of the program including good criteria, in terms of quality level improvement programs including good criteria, and when viewed from quality level certification programs also include good criteria. Recommendations that can be given to minimize the obstacles found are as follows. (1) Difficulties in determining the mechanism of screening human resources: university leaders should conduct human resources screening based on the need for qualifications following the field to be assigned later (in this case, managing online learning). (2) Unprepared understanding of lecturers and students in recognizing and using online learning is to provide encouragement and understanding to lecturers and students that online learning is essential to be known and understood to facilitate the learning process in higher education. (3) Lack of infrastructure needed in online learning is that online learning management must be able to make a priority list of facilities and infrastructure needed in the implementation of online learning and readiness of university leaders to facilitate it. (4) The lack of a budget used for the implementation of online learning is that leaders of universities should be able to find funding donors sourced from other parties or agencies outside the campus. (5) Rarely the socialization of online learning for all academic community that is expected leaders can routinely socialize the existence of online learning in helping the learning process both during meetings or other activities. (6) There are still lecturers and students who cannot operate online learning, which is regularly held workshops for the use of online learning. 


\section{References}

Abedi, J. (2002). A latent-variable modeling approach to assessing reliability and validity of a creativity instrument. Creativity Research Journal, 14(2), 267-276.

Agostinho, S., Meek, J., \& Herrington, J. (2005). Design methodology for the implementation and evaluation of a scenario-based online learning environment. Journal of Interactive Learning Research, 16(3), 229-242.

Griff, E. R., \& Matter, S. F. (2013). Evaluation of an adaptive online learning system. British Journal of Educational Technology, 44(1), 170-176.

Gündüz, A. Y., Alemdag, E., Yasar, S., \& Erdem, M. (2016). Design of a Problem-Based Online Learning Environment and Evaluation of its Effectiveness. Turkish Online Journal of Educational Technology-TOJET, 15(3), 49-57.

Hew, K. F., \& Cheung, W. S. (2014). Students' and instructors' use of massive open online courses (MOOCs): Motivations and challenges. Educational research review, 12, 4558.

Heirdsfield, A., Walker, S., Tambyah, M., \& Beutel, D. (2011). Blackboard as an online learning environment: What do teacher education students and staff think?. Australian Journal of Teacher Education (Online), 36(7), 1-16.

Kim, J., \& Seltzer, M. (2007). Causal inference in multilevel settings in which selection processes vary across schools.

Kumar, R., Chung, G. K., Madni, A., \& Roberts, B. (2015, June). First evaluation of the physics instantiation of a problem-solving-based online learning platform. In International conference on artificial intelligence in education (pp. 686-689). Springer, Cham.

Kupermintz, H., \& Roeser, R. (2002). Another Look at Cognitive Abilities and Motivational Processes in Science Achievement: A Multidimensional Approach to Achievement Validation. CSE Technical Report.

Means, B., Bakia, M., \& Murphy, R. (2014). Learning online: What research tells us about whether, when and how. Routledge

Moore, M. G., \& Kearsley, G. (2011). Distance education: A systems view of online learning. Cengage Learning.

Musingafi, M. C., Mapuranga, B., Chiwanza, K., \& Zebron, S. (2015). Challenges for open and distance learning (ODL) students: Experiences from students of the Zimbabwe Open University. Journal of Education and Practice, 6(18), 59-66.

Nadeak, B., Naibaho, L., Sunarto, S., Tyas, E. H., \& Sormin, E. (2021). Learning Management in Suburban Schools During the Midst of COVID-19. Psychology and Education Journal, 58(2), 1131-1139.

Nadeak, B., Juwita, C. P., Sormin, E., \& Naibaho, L. (2020). The relationship between students' critical thinking skills and the use of social media on learning outcomes during the Covid-19 pandemic. Jurnal Konseling dan Pendidikan, 8(2), 98-104.

Nadeak, B., Naibaho, L., \& Silalahi, M. (2020). COVID-19 and Students' Anxiety Management. International Journal of Innovation, Creativity and Change, 13(7), 1574-1587.

Newcomer, K. E., Hatry, H. P., \& Wholey, J. S. (2015). Handbook of practical program evaluation. John Wiley \& Sons.

Page, T., Thorsteinsson, G., Uden, L., \& Lehtonen, M. (2008). A Methodology for the Evaluation of Online Learning Resources. Journal of Educational Technology, 4(4), 16-27. 
Prasasti, T ET AL. (2019). The Effectiveness of Learning Media Folklore Text of North Sumatera Based on Blended Learning by 10th Grade Students of Vocational High SchoolHarapan Mekar-1 MedaN. Budapest International Research and Critics in Linguistics and Education (BirLE) Journal. P. 480-490

Seltzer, M., Choi, K., \& Thum, Y. M. (2002). Latent Variable Modeling in the Hierarchical Modeling Framework: Exploring Initial Status $X$ Treatment Interactions in Longitudinal Studies. CSE Technical Report.

Swan, K., Shen, J., \& Hiltz, S. R. (2006). Assessment and collaboration in online learning. Journal of Asynchronous Learning Networks, 10(1), 45-62.

Tyas, E. H., \& Naibaho, L. (2020). A harmony among of religious community is required amidst the covid-19 pandemic. International Journal of ResearchGRANTHAALAYAH, 8(9), 422-428.

Tyas, E. H., Sunarto, S., \& Naibaho, L. (2018). Evaluation of Students Centered Learning Learning Implementation by PPL FKIP-UKI Students at Mitra-PSKD School. Jurnal Selaras: Kajian Bimbingan dan Konseling serta Psikologi Pendidikan, 1(1), 69-80.

Voyce, J., Gouveia, M. J., Medinas, M. A., Santos, A. S., \& Ferreira, R. F. (2015). A Donabedian model of the quality of nursing care from nurses' perspectives in a Portuguese hospital: A pilot study. Journal of nursing measurement, 23(3), 474-484. Wahid, R et al. (2020). Digital Activism: Covid-19 Effects in Campus Learning. Budapest International Research and Critics in Linguistics and Education (BirLE) Journal. P. 1336-1342

Wicks, M. (2010). A National Primer on K-12 Online Learning. Version 2. International association for K-12 online learning.Poon, J. (2013). Blended learning: An institutional approach for enhancing students' learning experiences. Journal of online learning and teaching, 9(2), 271-288.

Wicks, D., Craft, B. B., Lee, D., Lumpe, A., Henrikson, R., Baliram, N., ... \& Wicks, K. (2015). An evaluation of low versus high collaboration in online learning. Online Learning, 19(4), n4.

Zhou, S., Gong, J., Xiong, G., Chen, H., \& Iagnemma, K. (2010, June). Road detection using support vector machine based on online learning and evaluation. In 2010 IEEE intelligent vehicles symposium (pp. 256-261). IEEE.

Zimmerman, C., \& Glaser, R. (2001). Testing Positive versus Negative Claims: A Preliminary Investigation of the Role of Cover Story on the Assessment of Experimental Design Skills. CSE Technical Report. 